Madrygal. Revista de Estudios Gallegos

ISSN: 1138-9664

\title{
Literatura, crítica y mercado del libro en De Mar a Mar (1942-1943): una lectura de la revista a la luz de las conexiones editoriales del exilio gallego en la Argentina
}

Federico Gerhardt ${ }^{1}$

Recibido: 27 de agosto de 2016 / Aceptado: 30 de decembro de 2016

Resumen. El presente artículo analiza las relaciones entre la literatura, la crítica y el mercado del libro en la revista literaria De Mar a Mar, publicada en Buenos Aires entre 1942 y 1943 por un grupo de exiliados de la Guerra Civil española, en su mayoría de ascendencia gallega. El análisis se enfoca en dos aspectos particulares de la revista: por un lado, en relación con su contenido, se abordan las noticias bibliográficas y las publicidades editoriales aparecidas en sus páginas; por otro lado, en relación con su contexto, se considera la labor desarrollada por sus directivos y colaboradores asiduos, en el mercado de la edición en la Argentina, el cual por entonces atraviesa su "época de oro". La puesta en relación de estos dos aspectos analizados echa luz con respecto a las conexiones editoriales que subyacen en la revista De Mar a Mar y que inciden en la composición de sus diferentes entregas.

Palabras clave: Industria editorial; revistas literarias; exilio gallego; Buenos Aires 1940-1943.

\section{[gl] Literatura, crítica e mercado do libro en De Mar a Mar (1942-1943): unha lectura da revista á luz das conexións editoriais do exilio galego na Arxentina}

Resumo. Este artigo analiza as relacións entre literatura, crítica e mercado do libro na revista literaria De Mar a Mar, publicada en Bos Aires entre 1942 e 1943 por un grupo de exiliados da Guerra Civil española, sobre todo galegos. A análise céntrase en dous aspectos específicos da revista: por unha banda, con respecto ao seu contido, analízanse as noticias bibliográficas e os anuncios editoriais publicados nas súas páxinas; por outra banda, en relación ao seu contexto, considérase o traballo dos seus directores e colaboradores habituais, no mercado editorial en Arxentina, que estaba vivindo daquela a súa "época de ouro". A ligazón destes dous aspectos analizados bota luz sobre conexións editoriais que fundamentan a revista De Mar a Mar e que inciden na composición das súas diferentes entregas.

Palabras chave: Industria editorial; revistas literarias; exilio galego; Bos Aires 1940-1943.

\section{[en] Literature, Criticism and Publishing Industry in De Mar a Mar (1942-1943): a Reading in the Light of Publishing Networks of Galician Exile in Argentina}

\begin{abstract}
This article analyzes the relationships between literature, criticism and the publishing market in the literary magazine De Mar a Mar, published in Buenos Aires between 1942 and 1943 by a group of exiles from the Spanish Civil War, mostly, descendents of Galician. The analysis focuses on two particular aspects of the magazine: on the one hand, in relation to its content, the paper examines the bibliographical news and the editorial advertising; on the other hand, in relation to its context, it is considered the work of its directors and regular collaborators in the book publishing industry in Argentina, which is in its "golden age". The linking of these two aspects analyzed sheds light in respect of the editorial connections that underlie De Mar a Mar and that influence in the composition of the successive issues of the magazine.
\end{abstract}

Keywords: Publishing Industry; Literary Magazines; Galician Exile; Buenos Aires 1940-1943.

\footnotetext{
Universidad Nacional de La Plata, Consejo Nacional de Investigaciones Científicas y Técnicas, Instituto de Investigaciones en Humanidades y Ciencias Sociales.

E-mail: fgerhardt@fahce.unlp.edu.ar
} 
Sumario. 1. De Mar a Mar: características materiales. 2. Dos rasgos programáticos. 3. Las conexiones editoriales del grupo interno. 4. Crítica y publicidad: el mercado del libro. 5. Dos homenajes y una editorial: Galdós y Machado, y Losada. 6. Crítica de soutien y antifascismo, de Nova a Poseidón. 7. A modo de cierre: la continuidad de un proyecto y de sus relaciones editoriales. 8. Referencias bibliográficas.

Como citar: Gerhardt, F. (2017): "Literatura, crítica y mercado del libro en De Mar a Mar (1942-1943): una lectura de la revista a la luz de las conexiones editoriales del exilio gallego en la Argentina", Madrygal. Revista de Estudios Gallegos 20 (Núm. especial), pp. 135-146.

\section{De Mar a Mar: características materiales}

De Mar a Mar. Revista literaria mensual comenzó su andadura en Buenos Aires, en diciembre de 1942, y su séptimo y último número está fechado en junio de 1943. Encabezaban la revista, con el cargo de secretarios, dos escritores exiliados de la Guerra Civil española, Lorenzo Varela y Arturo Serrano-Plaja ${ }^{2}$, a los que se sumaban, en lo que podría denominarse "grupo interno" (Osuna 2004: 43 e ss.) y como colaboradores asiduos, otros tres exiliados de ascendencia gallega, al igual que Varela: el escritor Rafael Dieste, el poeta Arturo Cuadrado, y el artista plástico y escritor Luis Seoane, encargado de los aspectos gráficos de la publicación, con la colaboración del artista gráfico italiano refugiado en la Argentina, Attilio Rossi ${ }^{3}$.

A lo largo de sus siete números, De Mar a Mar mantuvo un formato de 23,5 cm por $16 \mathrm{~cm}$, con tapas de cartulina blanca con la reproducción de un dibujo en el centro y con la inclusión de hojas de papel satinado para fotografías e ilustraciones interiores ${ }^{4}$. Cada número contaba con alrededor de 50 páginas y se imprimía en los talleres de la Imprenta López, ubicada en el número 666 de la porteña calle Perú. Las referidas características materiales de la revista incidían en su precio de venta, que se fijaba en $\$ 1.50^{5}$.

Desde el subtítulo, la revista propone una frecuencia mensual aunque ciertos datos de sus propias páginas, ya señalados por abordajes previos (Dolinko 2010), así como de las páginas de otras publicaciones periódicas, permiten deducir una frecuencia irregular, y un desfasaje entre la datación de cada número en tapa y la fecha efectiva de publicación. Asimismo, este desfasaje puede advertirse en las páginas de otras publicaciones periódicas relacionadas con De Mar a Mar. Por un lado, en Correo Literario, periódico quincenal dirigido y promovido por el mismo grupo de intelectuales, apareció hasta el número 10, del 1 de abril de 1944, una publicidad que invitaba a los lectores a suscribirse a la anterior revista. Por otro lado, la revista Sur reseña del siguiente modo la aparición del $\mathrm{n}^{\mathrm{o}} 1$ de De Mar a Mar:

Nueva revista que agrupa a conocidos escritores, muchos de ellos expatriados: "Estamos decididamente con los pueblos libres y deseamos su rápida victoria sobre el nazismo, el falangismo y el fascismo". Un homenaje a Miguel Hernández que incluye una selección de sonetos del poeta, un dibujo de Colmeiro, una égloga de Rafael Alberti. Además, las siguientes colaboraciones: Nuestra breve vida rodeada está de sueño, por Eduardo Mallea, De cómo vino al mundo Félix Muriel, por Rafael Dieste; El valle del Paraíso, por Serrano Plaja; Notas, por

2 Previamente, ambos habían compartido la redacción de dos revistas emblemáticas de la Guerra Civil y el exilio: Hora de España en la Península y Romance en México, respectivamente. Véase Caudet 2004: 181-183, PérezRodríguez 2005.

3 Los cuatro gallegos mencionados constituyen el núcleo del grupo a veces identificado como "la peña gallega del Tortoni” (González Ledo 2008) o, simplemente, el "Grupo Tortoni” (Pérez-Rodríguez 2004), por el conocido café de la ciudad de Buenos Aires en que se reunía.

4 La revista contaba con una serie de secciones gráficas: Testimonios (Imágenes de la guerra), Genio y figura (Retratos de personalidades), Del linaje que no muere (Reproducciones de obras de arte), De un mar a otro (Curiosidades y disparates), en las primeras dos entregas, y, a partir del número 2, Colaboraciones, dedicada, fundamentalmente, a la obra plástica de artistas contemporáneos del campo cultural argentino.

5 Para poner este precio en contexto, aunque sea restringido al campo de la producción editorial, cabe contrastarlo con los precios de venta de los libros publicitados en la misma revista, que se mueven en un arco que va desde los $\$ 3$ que costaban los libros en rústica de Sudamericana o Losada, hasta las ediciones de arte, encuadernadas en tela y con reproducciones a color de Poseidón, que rondaban los \$20. Por otro lado, el precio de De Mar a Mar podría compararse con el de la siguiente publicación dirigida por Varela, junto a Seoane y Cuadrado -secundados por Javier Farías como secretario-, Correo Literario, editada en papel común y gran formato, con 8 páginas por número, cuyo número inicial del 15 de noviembre de 1943 salió con el precio de $\$ 0.30$. 
José Otero Espasandín, Serrano Plaja y Lorenzo Varela. La parte gráfica agrupa una fotografía de guerra, un retrato de Toulouse-Lautrec, un desnudo de Renoir, viñetas de Rossi y Seoane. Es elogiable la presentación material de la revista. (Sur $\mathrm{n}^{\circ} 105$, p. 114)

Lo significativo de esta noticia sin firma sobre la primera entrega de De Mar a Mar, reside en este caso en que la misma se publica en el $\mathrm{n}^{\circ} 105$ de Sur, del 1 de julio de 1943, es decir, un mes después de la fecha que lleva en tapa el séptimo y último número de la revista reseñada, según se ha mencionado anteriormente.

\section{Dos rasgos programáticos}

Si bien no abundan en De Mar a Mar los textos explícitamente programáticos, el número inaugural de diciembre de 1942 incluye una presentación sin firma en la que se plantean los principios generales que rigen la publicación, y de la que proceden las líneas citadas en la reseña de Sur:

Una revista que sale a luz en estos momentos, tiene, de un modo más imperativo que si naciese en otros apacibles, la obligación de reflejar de alguna manera el tiempo a que pertenece. (...) Pues creemos que a nadie puede darle lo mismo el resultado de la actual contienda mundial, porque eso sería tanto como despreocuparse por la existencia misma del hombre y del pensamiento. A nosotros desde luego no nos es igual éste o el otro resultado. Estamos decididamente con los pueblos libres y deseamos su rápida victoria sobre el nazismo, el falangismo y el fascismo. De Mar a Mar se inicia al calor fraternal de unos cuantos amigos, europeos y americanos, unos en Buenos Aires, otros dispersos por el continente. (n ${ }^{\circ} 1$, pp. 5-6)

En este texto inicial ya aparecen dos aspectos programáticos que subyacen a la revista durante toda su andadura: en primer lugar, la continuidad en la resistencia antifascista en el contexto de la Segunda Guerra Mundial, considerada como continuidad de la Guerra Civil española; y, al mismo tiempo, la voluntad de convertirse en espacios de integración con el campo cultural argentino -con proyecciones en otros países de América latina- e instrumentos de religación con intelectuales exiliados en otros puntos del continente. A la distancia, el propio Lorenzo Varela recordaba la publicación haciendo hincapié en los mismos puntos, refiriéndose a los "intentos claros de integración con los intelectuales iberoamericanos", y caracterizándola del siguiente modo:

Fue De Mar a Mar el lugar de encuentro de los españoles del destierro con los argentinos en permanente búsqueda de su libertad (...) una revista interamericana con la presencia activa de huéspedes españoles, alzada como un estandarte del mundo libre frente a la agresión, poderosa y solapada, cuando no declarada y aparentemente invencible, del fascismo. (Varela 2001: 167, 168-169)

Esta voluntad de integración puede observarse, por un lado, en la nómina de colaboradores de los sucesivos números, que incluye tanto a exiliados como a escritores argentinos, junto a otras firmas iberoamericanas. Junto a los secretarios Varela y Serrano-Plaja, y los demás integrantes del grupo fundador Seoane, Cuadrado y Dieste, la lista de autores que participan del primer número de De Mar a Mar está compuesta por los siguientes intelectuales y artistas: los exiliados Manuel Colmeiro, José Otero Espasandín, Ramón Pontones, Rafael Alberti y Francisco Ayala, el también español y republicano Guillermo de Torre, y los argentinos Enrique Anderson Imbert, Horacio Butler, Eduardo Mallea, Ricardo Molinari, Eduardo Sacriste, el italiano Attilio Rossi -quien colabora con Seoane en los aspectos gráficos de la revista- y el brasileño Newton Freitas. La lista, puesta al frente del $n^{\circ} 1$, se cierra con un etcétera que se irá completando en los números siguientes con la incorporación de españoles como Antonio Sánchez Barbudo y Alejandro Casona, de argentinos como José Luis Romero y Luis Baudizzone, y, en muy menor medida, uruguayos y brasileños.

Por otro lado, la intención de convertir a la revista en un espacio de interacción con el campo cultural local se hace patente en la atención prestada a la producción intelecutal y artística desarrollada en la región y, muy especialmente, en la Argentina, y con particular atención a la industria editorial. A este fin se dedicaba una extensa sección denominada "Mirador", que podía albergar novedades de cine, teatro y artes plásticas, pero que estaba mayormente ocupada por reseñas de libros recientemente publicados. Agrupados bajo el título "Libros", estos textos críticos ocupaban un espacio importante en la revista, entre seis y diez páginas de las cincuenta que -en promedio- componían cada número. Otro aspecto destacable de la sección 
bibliográfica reside en que, salvo contadas excepciones, las reseñas publicadas en De Mar a Mar estaban a cargo de los secretarios de la revista, Varela y Serrano-Plaja, y de Otero Espasandín, Cuadrado, Dieste y Farías. Estas dos características de la sección "Libros", extensión considerable y amplia mayoría de las firmas de exiliados, particularmente, los gallegos, puede explicarse en virtud de la labor editorial desarrollada por los responsables de De Mar a Mar, paralelamente a estas publicaciones periódicas.

\section{Las conexiones editoriales del grupo interno}

Nombres como los de Luis Seoane, Arturo Cuadrado, Rafael Dieste y Lorenzo Varela habían desempeñado un papel destacado en el mercado de la edición argentino, incursionando en un momento particularmente propicio de la actividad, dentro del periodo del "auge de la industria cultural” (Rivera 1998: 94) y, más específicamente, en los inicios de la conocida como "época de oro de la industria editorial" en la Argentina (De Diego 2006: 91), que se suele ubicar entre los años 1938 y 1955, aproximadamente. Apenas un breve repaso de algunos puntos de su actividad profesional da cuenta de algunos vínculos de los promotores de $D e$ Mar a Mar con el mercado editorial argentino ${ }^{6}$.

Al entrar Seoane y Cuadrado en Emecé, en 1940, comenzaron a publicar dos colecciones dedicadas a la literatura gallega: Hórreo y Dorna, cuyos volúmenes incluían las más de las veces, láminas e ilustraciones del propio Seoane. Además, en la misma editorial, Seoane creó la colección Buen Aire, en colaboración con Cuadrado y Luis María Baudizzone ${ }^{7}$, fundador y director, a su vez, de Editorial Argos.
En 1942, habiéndose retirado de Emecé, Seoane y Cuadrado fundaron, la editorial Nova, en sociedad con la Imprenta López, en cuyos talleres se imprimían por entonces los volúmenes de, entre otros sellos, Losada, así como de las antes mencionadas colecciones de Emecé. En el seno de la Editorial Nova, Varela dirigió la colección Páginas Íntimas, la Serie Siglo XIX y la Serie Romántica, colecciones breves las tres que incluyeron, mayormente libros de o sobre autores franceses, casi siempre en traducciones del mismo Varela o de Arturo Serrano-Plaja. Por su parte, también en Nova, Cuadrado dirigió las colecciones Pomba y, junto con Luis Seoane, Camino de Santiago. En ellas tuvieron lugar obras de, por ejemplo, Varela, además de autores como Rafael Dieste, que por entonces se desempeñaba como Director del Departamento Editorial de Atlántida, sello en el que además dirigió la Colección Oro, donde vieron la luz títulos de, entre muchos otros, José Otero Espasandín, Javier Farías, Lorenzo Varela, Francisco Ayala y el propio Dieste. Estos dos últimos, Ayala y Dieste, junto a Rafael Alberti, fundaron, en aquel mismo año de 1942, la editorial Nuevo Romance, cuyo concesionario exclusivo para la venta fue Losada. Y a propósito de esta mención, a esta serie de conexiones que se tejen en torno a la revista cabe agregar además que los mencionados así como otros de los colaboradores se hallaban vinculados, ya desde fines de los 30, a las editoriales Losada, donde Seoane coincidió con Attilio Rossi, y Sudamericana, como es el caso de Dieste ${ }^{8}$. Otro tanto puede anotarse con respecto a Poseidón, casa editora fundada en 1942 por el catalán Joan Merli, en la cual Varela se desempeñó como autor y traductor de libros $^{9}$, y Seoane como maquetador e ilustrador.

\footnotetext{
Un abordaje más extenso de estos proyectos editoriales puede encontrarse en Gerhardt $2015 \mathrm{~b}$.

Y con José Luis Lanuza, según Pochat 1991.

Considérese, por ejemplo, el proyecto inédito de Luis Seoane para un convenio entre la Editorial Losada y el Centro Gallego de Buenos Aires, para la creación de una "Biblioteca de Escritores Gallegos", fechable en 1939 (Gerhardt 2015a). En cuanto a Dieste, ya en 1939 ve la luz su traducción de Terre des hommes de Antoine de Saint-Exupéry. Cabe presumir que el temprano vínculo con Sudamericana habría estado dado por la relación de Dieste con escritores ligados a la revista Sur, y en particular con Oliverio Girondo, miembro del grupo fundador de aquella editorial, quien organiza una recepción para el escritor gallego a escasos días de su llegada a la Argentina, según anota el propio Rafael Dieste en carta a su hermano Enrique del 21 de julio de 1939 (1995: 152). Por su parte, Rossi -figura clave en el desarrollo de las artes del libro en esta etapa de la industria en la Argentina-, participa de ambos círculos, ya que forma parte del primer staff editorial de Losada, tras haber salido de Espasa-Calpe Argentina junto a Gonzalo Losada y Guillermo de Torre, quien a su vez lo acercó a la revista Sur, de la que fue crítico de arte (véase Sánchez Vigil y Olivera Zaldua 2012).

9 Por ejemplo, Poseidón edita en 1943 las Curiosidades estéticas de Charles Baudelaire, de cuya selección, traducción y prólogo se encarga Lorenzo Varela. La publicidad del libro, incluido en la Colección Críticos e Historiadores del Arte puede encontrarse en los números 3, 5 y 6 de De Mar a Mar.
} 


\section{Crítica y publicidad: el mercado del libro}

Dado el ya mencionado auge de la industria editorial argentina en el periodo, y en consonancia con esta destacada participación de los promotores de De Mar a Mar en el mercado del libro, la sección bibliográfica de la revista otorgó un papel preponderante a los libros editados en Buenos Aires por los sellos a los que se hallaba ligado el grupo fundador, $y$, en particular, a las obras de los exiliados. Como una suerte de contraparte, las citadas editoriales ${ }^{10}$ hacían su aporte a la revista mediante la publicidad, generalmente, a página completa, que ocupaba alrededor de seis páginas en cada número, en folios agregados al principio y al final de cada entrega. La observación, a título de ejemplo, del primer número de De Mar a Mar permite advertir esta serie de relaciones que estructuran la composición de la revista, articulando sus partes, y que se reitera en los números posteriores.

Tras la cubierta y antes de la portada y los contenidos, el volumen presenta, en tres folios ciegos, a una por página, la publicidad de las novedades de las editoriales Sudamericana, Poseidón y Losada. Tras ellos, un cuarto folio publicita al sello Claridad, dirigido por el andaluz Antonio Zamora.

Ya en la sección "Libros" se incluyen dos reseñas extensas, ambas a cargo de Lorenzo Varela: la primera, del libro Goya, de Ramón Gómez de la Serna, editada por Poseidón $\left(\mathrm{n}^{\mathrm{o}}\right.$ 1, pp. 47-48) e incluida en la publicidad con que se abría el número; la segunda, de $i E h$, los toros!, libro que reúne poemas taurinos de Rafael Alberti con grabados de Luis Seoane $\left(\mathrm{n}^{\mathrm{o}} 1\right.$, pp. 45-47). En este caso, se trata de una edición que estuvo al cuidado de Attilio Rossi, en cuya labor se detiene particularmente Varela, incluso más que en los propios poemas de Alberti-aunque menos que en los grabados de Seoane-, cerrando su reseña con este párrafo:

Sería desagradecimiento cerrar esta nota sin felicitar a Attilio Rossi por haber cuidado-como dice el colofón- la edición de ¡Eh, los toros! Desde la festival portada del libro, inspirada en los viejos carteles de las corridas de toros, con su banderilla verde oliva y el capote, sobre los cuernos de la cabeza grabada por Seoane para el frente del libro, color rojo toro, desvanecido en negro tierra por las puntas; desde las firmas de los autores, con aquella caligrafía en que se imprimían los nombres de los [sic] espadas en las corridas mayores, hasta la disposición interna, este álbum espléndido de grabados y versos que tratan de toros, hace honor al bien ganado prestigio de Attilio Rossi, a quien tanto le deben las artes gráficas de América. ( $\mathrm{n}^{\mathrm{o}} 1, \mathrm{p}$. 47)

Acompañan a éstas en la sección bibliográfica las noticias de tres novelas traducidas publicadas por Sudamericana, Losada y Claridad, a cargo de Varela ( ${ }^{\circ} 1$, pp. 50-51), Otero Espasandín (pp. 42-43) y Serrano-Plaja (pp. 48-50), respectivamente. Tras la sección "Libros" el número incluye dos nuevos anuncios a página completa: uno, de la casa editora Atlántida; el otro, de la Editorial Nova presentando sus cinco nuevas colecciones.

Esta práctica, que en ocasiones ha sido caracterizada como "crítica de soutien" (Zuleta 1999: 58), presenta varios ejemplos en los números posteriores, en los que pueden observarse este diálogo entre la crítica de libros y la publicidad editorial, ya sea dentro del mismo número, o entre dos o más números. Así, por ejemplo, tanto en la publicidad ubicada al comienzo del $n^{\circ} 1$ como en la emplazada al final del $n^{\circ} 2$, se encuentra una página dedicada a las novedades de la Editorial Poseidón, entre las que figura Tintoretto, de Julio Payró, publicado en la colección Biblioteca Argentina de Arte. Ese mismo libro es reseñado en el segundo número por Arturo Cuadrado, cuyo texto se cierra destacando las cualidades materiales de la edición:

Con este decir y con una cuidada Biografía sintética y con una relación de sus principales obras y con 47 reproducciones en negro y una en color, bien escogidas y bien reproducidas, basta para afirmar que este volumen de Julio Payró sobre Tintoretto es el primero y más necesario para una total comprensión del incomprendido genio veneciano. $\left(\mathrm{n}^{\mathrm{o}} 2, \mathrm{p} .54\right)$

10 También la Imprenta López, cuya publicidad puede encontrarse en los números 2, 3 y 6 de De Mar a Mar, a página completa en los dos primeros. 
Otro ejemplo similar relacionado con la Editorial Poseidón puede señalarse en relación con el Tratado del paisaje de André Lothe. E1 libro del pintor francés, traducido por Julio Payró, es incluido en la publicidad editorial de los números 3, 4 y 5, destacándose, al igual que en la reseña antes citada de Tintoretto por Cuadrado, las características materiales del libro: "64 grabados en negro y 4 en color. Gran formato; el libro solicitado por los artistas y aficionados al arte. Encuadernado en tela". En uno de los números citados, más precisamente en el $n^{\circ} 4$, Lorenzo Varela firma una reseña del Tratado del paisaje que, en consonancia con la publicidad, se cierra con un elogio de la edición: "La Editorial Poseidón, que inicia con este libro una colección prometedora, «Colección de los Tratados», ha hecho una edición a tono con la brillantez y el buen gusto que era de esperar en ella. La traducción, de Julio E. Payró, correcta y esmerada" (nº 4, p. 41).

Tal como sucede con Poseidón, aunque en mayor medida considerando las circunstancias, otra de las editoras a las que se hallaban ligados los editores de De Mar a Mar, la Editorial Nova, también participa de este doble juego entre la publicidad y la sección bibliográfica de la revista. Así, por ejemplo, podemos encontrar en un aviso publicitario del $n^{\circ}$ 2 la biografía Don Diego Gelmírez de Manuel Murguía, de la colección Camino de Santiago, que será reseñada en el número siguiente por José Otero Espasandín, quien cierra el elogio del libro apelando a un público compuesto por exiliados e inmigrantes españoles y, especialmente, gallegos, haciendo referencia al mérito que corresponde "al libro que reseñamos y que desearíamos leyesen cuantos españoles y gallegos llegaron a esta parte del Atlántico con una visión muy somera o nula de las pasadas glorias de su país de origen" $\left(\mathrm{n}^{\mathrm{o}} 2, \mathrm{p} .52\right)$.
Otro ejemplo en relación con la Editorial Nova puede encontrarse en los primeros números. En el $n^{\circ} 1$, un aviso presenta las cinco nuevas colecciones del sello de Seoane y Cuadrado, con el título que abre cada una de ellas, entre las que se cuenta la colección Mar Dulce y Huaman Poma [sic], respectivamente. En el no 3, nuevamente se presentan las últimas publicaciones de la Editorial Nova, divididas por colecciones, entre ellas Mar Dulce, ahora con dos títulos brevemente descriptos: Huaman Poma de Ayala y Guadalupe Posada [sic]. Y en el número siguiente, el 4, el brasileño Newton Freitas firma una reseña de los dos libros que inauguran la colección Mar Dulce -en la que también verán la luz volúmenes a su cargo- ${ }^{11}$, Guaman Poma y La calavera y otros grabados de Guadalupe Posada, elogio que se abre recordando asimismo el precedente de Buen Aire en Emecé:

La mera elección de estos dos interesantes tomos para iniciar una colección, bastaría por sí misma para garantizar su criterio artístico y su rectitud literaria. No obstante, es preciso considerar que esta Colección está dirigida por Luis M. Baudizzone y por Luis Seoane, que junto a Arturo Cuadrado fundaron, y dirigieron hasta el número 15, la Colección Buen Aire. En aquella Colección, hoy tan conocida, quedó demostrada la capacidad de sus directores, tanto en la selección de los textos como en el cuidado gráfico y en la confección artística. Era, pues, de esperar que Mar Dulce se presentase como se presentó, dadas las credenciales de quien la dirige. Y basta hojear estos dos tomos recientemente aparecidos para constatar esta verdad. ( $\mathrm{n}^{\circ} 4$, p. 41)

Además de los antes referidos a propósito de Nova y Poseidón, pueden citarse ejemplos de otras editoriales con las que estaban vinculados los integrantes del grupo interno, entre las que se destaca Losada ${ }^{12}$. Encabezando la

11 Se trata de Amazonia. Leyendas Ñangatú (1943), seleccionadas por Newton Freitas y con una noticia de su autoría, y Garibaldi en América (1946), escrito por el propio Freitas. Antes, cuando Seoane y Cuadrado todavía formaban parte de Emecé, el escritor brasileño había publicado con ellos y Luis Baudizzone un libro en la colección Buen Aire: Alôs Afro-Brasileños (1942).

12 Y con esta editorial, otros sellos como Nuevo Romance, la distribución de cuyos volúmenes estaba a cargo de Losada, por lo que la publicidad de esta editorial los incluía sin discriminarlos de los títulos propios, tal el caso del aviso ubicado al principio del $\mathrm{n}^{\mathrm{o}} 2$, en que, junto con otros títulos de Losada, se publicitan como novedades La lozana andaluza de Francisco Delicado y Guerras civiles de Granada de Ginés Pérez de Hita, sin aclarar su pertenencia al sello Nuevo Romance, empresa editorial que, como se mencionó anteriormente, llevaron adelante Rafael Dieste, Rafael Alberti y Francisco Ayala. Este último, precisamente, tuvo a su cargo la edición del libro del Arcipreste de Hita, tarea elogiada por José Luis Romero en la respectiva reseña, publicada en el n ${ }^{\circ} 5$ de $D e$ Mar a Mar (pp. 38-39). 
publicidad de las novedades de dicha editorial, en la primera página del n ${ }^{\circ} 2$ de De Mar a Mar, se encuentra el aviso del libro Maruja Mallo, que destaca, entre sus características, el prólogo de Ramón Gómez de la Serna y la edición en un volumen con "63 grabados en negro y 9 en color (...) a gran formato encuadernado en tela". En el número siguiente de la revista verá la luz la reseña del libro dedicado a la pintora gallega, relacionada no sólo con Losada sino también con el Grupo Sur y con la Editorial Atlántida, a cuya intercesión se debió la entrada en la empresa, de Rafael Dieste, junto a otros exiliados gallegos del grupo interno de De Mar a Mar como Luis Seoane y colaboradores asiduos de la publicación como José Otero Espasandín ${ }^{13}$. Si bien no deja de destacar las virtudes de la obra plástica de Maruja Mallo, el texto de Arturo Cuadrado hace hincapié en las acertadas cualidades materiales de la edición:

Si la pintura de Maruja Mallo tiene una incontenible vitalidad y una sana alegría de espacio, había que inventar el papel y la máquina que fuesen capaces de ordenar ese mundo que gira desde el fondo del mar hasta el fruto de la tierra. Así, en el misterio de este libro, al pasar de las hojas, se olvida uno de la biblioteca para instalarse en un museo exótico en donde la plástica entona un himno a las artes gráficas que han producido el milagro creando una nueva pasión. Adolecen la mayoría de los libros de arte de orden y ritmo. La mayor parte de ellos cansan y fatigan, como las veloces visitas a las galerías de arte. Necesidades o apremios sobrecargan la impresión que se convierte en asfixia. Y en este libro que hoy comentamos hay un juego de blancos que nos llevan tranquilamente por un camino de exposiciones desde 1928 hasta 1942. $\left(\mathrm{n}^{\circ} 3\right.$, pp. 52-53)

Precisamente, sobre el final de la reseña se encuentra la mención de los responsables de la bien ponderada edición llevada cabo por dos agentes de las artes del libro íntimamente ligados a De Mar a Mar, el elogio de cuya tarea posterga incluso la atención dedicada a la propia pintora: "A la Imprenta López le debemos la esmerada impresión, bajo el sagaz y cariñoso cuidado de Attilio Rossi. Y quede para otra vez hablar de la pintura de Maruja Mallo..." (no 3, p. 54).

Estas relaciones entre el contenido de la sección "Mirador" y la publicidad de las editoriales relacionadas con la revista no se limitan a las noticias bibliográficas ${ }^{14}$. Fuera de los textos sobre "Libros", entre las notas dedicadas a la actualidad artística pueden encontrarse otros casos, de los que cabe referir dos que involucran a artistas cuyos nombres ya han sido citados. En el no 2 de De Mar a Mar, Lorenzo Varela firma una nota titulada "Algo sobre Ramón Pontones que se nos vá [sic] a México" (pp. 47-48), y, cerrando el número, como última publicidad y a página completa, se anuncia que "acaba de aparecer" 10 dibujos de Ramón Pontones, en la Editorial Nova y con una nota sobre el pintor escrita por el propio Varela. Algo similar puede observarse en el $\mathrm{n}^{\mathrm{o}} 5$ de la revista, en el cuarto de los folios ciegos incluidos al principio, donde la publicidad de los últimos títulos de la Editorial Nova se abre con Diez dibujos de Attilio Rossi, acompañados por un estudio preliminar de Guillermo de Torre. Más adelante, ya en la sección "Mirador" y abriendo las noticias sobre "Exposiciones" se encuentra una noticia, firmada por José Otero Espasandín con las iniciales O. E., sobre la muestra de "Óleos y Dibujos" de Rossi en el Salón Impulso del barrio porteño de La Boca, en la que se destaca la evolución artística del italiano, y se retoman algunas de las observaciones sobre su pintura pronunciadas por Rafael Dieste en la conferencia escrita para la ocasión ${ }^{15}$.

13 A propósito de las relaciones de Maruja Mallo con el campo cultural argentino de la época, incluyendo los vínculos mencionados, véase la edición y el análisis de la correspondencia de la artista gallega con Alfonso Reyes, publicados por María Antonia Pérez Rodríguez en Madrygal (Pérez Rodríguez 2013 y 2014).

14 Podría, incluso, incidir en las secciones gráficas. Por ejemplo, en el no 6 (pp. 8-9), en la sección "Del linaje que no muere" se introduce una reproducción de Degollación de los inocentes. La obra pertenece a Lucas Cranach (el viejo), sobre el cual había publicado en fecha reciente una monografía la Editorial Poseidón, según se puede observar en la publicidad editorial de ese mismo número. Además, este libro había sido publicitado junto con otros en el número anterior de De Mar a Mar (n $\left.{ }^{\circ} 5\right)$.

15 En relación con estos últimos ejemplos, es oportuno recordar que, como señala Jorge Rivera (1998: 97), "el auge de los libros ilustrados y de las historias del arte se produjo en 1943, con la cifra excepcional de 631 apariciones". 
Junto a estos ejemplos, las relaciones entre el contenido de las páginas de De Mar a Mar y el mercado de la edición, pueden también leerse en dos de los tres homenajes brindados por la revista a figuras representativas de las letras españolas.

\section{Dos homenajes y una editorial: Galdós y Machado, y Losada}

El primer número de De Mar a Mar incluye un homenaje al poeta Miguel Hernández, compuesto por un dibujo de Manuel Colmeiro, una selección de sonetos de El rayo que no cesa y un fragmento de la "Égloga fúnebre a tres voces y un toro para la muerte lenta de un poeta" escrita por Rafael Alberti, director de la colección Rama de Oro de la Editorial Schapire, en la cual, a fines ese mismo año de 1942, se editará El rayo que no cesa y otros poemas (1934-1936), con prólogo y epílogo biográfico del propio Alberti. No obstante esta coincidencia, es en los otros dos homenajes en los que puede advertirse un correlato con el mercado editorial de Buenos Aires y, particularmente, con las ediciones de Losada.

El año 1943 y con motivo del centenario del nacimiento de Benito Pérez Galdós, el $n^{\circ}$ 5 de De Mar a Mar está dedicado casi íntegramente a la figura y a la obra del novelista canario, con textos de reconocidas firmas españolas y argentinas, ya sea trabajos previamente publicados, tal el caso de "Galdós, historiador del siglo XIX" de Ricardo Rojas, extraído de su libro Retablo español, editado por Losada en 1938; ya colaboraciones originales, como "De Cervantes a Galdós" de Guillermo de Torre. Coincidiendo con la efeméride, Losada incrementa significativamente la edición de novelas galdosianas en su Biblioteca Contemporánea, dirigida precisamente por De Torre, sumando a las tres editadas en 1939 (Trafalgar, El amigo Manso y Gerona) y las dos de 1942 (Fortunata y Jacina y Doña Perfecta), seis títulos en 1943: La fontana de oro, Nazarín, Halma, Tristana Misericordia y La loca de la casa.
Además, en este mismo año, Losada edita un título capital de la bibliografía galdosiana, el estudio de conjunto Vida y obra de Galdós, de Joaquín Casalduero.

En virtud de las conexiones entre De Mar a Mar y Losada, esta actividad editorial en torno a la obra de Benito Pérez Galdós puede leerse en relación con la revista, no sólo a través de la publicación de un número homenaje que incluye firmas e incluso textos del catálogo de la citada editorial - como el citado ensayo de Rojas- ${ }^{16}$, sino también a través de la publicidad. El aviso de las novedades de Losada que ocupa por completo una de las páginas iniciales del $\mathrm{n}^{\mathrm{o}} 1$, incluye entre los títulos Doña Perfecta. Ya en 1943, la página publicitaria de Losada se abre con el anuncio de la edición, conmemorativa del centenario, de La fontana de oro, primera novela de Galdós, con prólogo de Arturo Capdevila ${ }^{17}$. Y en el $n^{0} 5$, dedicado al novelista, entre las novedades anunciadas por Losada se encuentran Nazarín, Halma y Tristana, títulos a los que se suma el mencionado estudio de Casalduero, Vida y obra de Galdós. De este modo, todos los títulos galdosianos publicados por Losada en el año del centenario del nacimiento del escritor, con la sola excepción de un par-puede conjeturarse que por haber sido publicados, aunque en 1943, posteriormente al cese de la revista-, fueron recogidos por la publicidad editorial de De Mar a Mar, en su mayoría en el $n^{\circ} 5$, precisamente dedicado a homenajear a Galdós. De modo similar a lo sucedido con el escritor canario, las páginas de De Mar a Mar y el catálogo de Losada dialogan en torno a la obra de otro de los autores homenajeados, Antonio Machado.

El n ${ }^{\circ} 2$ de De Mar a Mar se abre con un texto sin firma dedicado "al poeta de la España que supo alzar la muralla de sus corazones a las huestes de la barbarie, desatada ahora sobre el planeta" ( $\left.\mathrm{n}^{\mathrm{o}} 2, \mathrm{p} .7\right)$. A propósito de este recuerdo de la figura del escritor como emblema de la resistencia antifascista, y en relación con el mercado editorial argentino, resulta

16 En ese momento, en la Biblioteca Contemporánea ya había sido publicado Blasón de plata de Rojas. También podría citarse el caso de otro de los colaboradores del número homenaje de De Mar a Mar, Alejandro Casona, quien para entonces había aportado también un volumen al catálogo de la célebre colección de Losada, con sus obras $L a$ sirena varada y Prohibido suicidarse en primavera.

17 Al año siguiente, Losada publicará el libro El pensamiento vivo de Galdós, del propio Capdevila. 
oportuno recordar que el nombre de Antonio Machado constituyó un significativo punto en común entre los catálogos de dos de las colecciones de bolsillo más relevantes de la historia editorial argentina: la ya mencionada Biblioteca Contemporánea de Losada, y la Colección Austral de Espasa-Calpe ${ }^{18}$. Ésta última había publicado una edición de sus poesías completas, recortadas y acompañadas por un prólogo de Dionisio Ridruejo que pretendía apropiarse de la figura del poeta para el régimen franquista, considerándolo ajeno a las convicciones políticas $^{19}$.

Por su parte, tras haber también publicado ese mismo año unas poesías completas, Losada incorporará en 1943 dos nuevos títulos de Machado a su Biblioteca Contemporánea: Juan de Mairena y Abel Martín. Tal como sucede con varios de los libros de la editorial Losada, estos títulos no sólo serán publicitados a través de los avisos de la editorial en De Mar a $\operatorname{Mar}\left(\mathrm{n}^{\circ} 3 \mathrm{y} \mathrm{n}^{\mathrm{o}} 5\right)$, sino que además, en el caso del primero, y de acuerdo con las prácticas críticas antes referidas, será objeto de una reseña firmada por uno de los secretarios de la revista. El texto de Arturo Serrano Plaja, precisamente, resalta en su lectura del heterónimo de Machado la dimensión política de su pensamiento, destacando como "uno de sus principales méritos (...) no desdeñar o hacer como que desdeñaba los problemas políticos y sociales" $\left(\mathrm{n}^{\mathrm{o}}\right.$ 3 , p. 47). En este punto puede observarse cómo en ocasiones esta práctica caracterizada como crítica de soutien, presenta algunos ejemplos interesantes en los que, además, se conjuga, de diferentes formas, con el antes mencionado posicionamiento antifascista.

\section{Crítica de soutien y antifascismo, de Nova a Poseidón}

En 1942, la Editorial Nova publicó, dentro de su colección Pomba, el poemario Torres de amor, de Lorenzo Varela, incluido en los anuncios publicitarios de los tres primeros números de De Mar a Mar. A su vez, una reseña firmada por José Otero Espasandín y publicada en el $n^{\circ} 2$, da cuenta de la reciente edición. Antes de cerrarse con el elogio de la edición y las diferentes características materiales del libro, destacando su influencia en el auge de la industria editora de entonces, el texto dedica unas líneas a la presunta negativa de Emecé a publicar el poemario por razones políticas, una de las causas probables de la salida de Cuadrado y Seoane de dicho sello en 1942, a la que alude Otero Espasandín ${ }^{20}$ :

Este libro de Lorenzo Varela aparece, además, envuelto en una aureola envidiable, lo han publicado dos compatriotas que desde hace unos años vienen dando a sus ediciones el rango de las mejores, y que han sabido sacrificar las ventajas económicas que empresas de ambigua condición les ofrecían a cambio de una solapada contemporización con los agentes del totalitarismo franquista. Prueba de su fe en su apostolado la constituye el hecho de reanudar las brevemente interrumpidas labores editoriales con un libro de versos de un autor, formado en las barricadas de la lucha de España por su independencia interna y externa, factores todos que cualquier otro editor no hubiera enfrentado en el clima que hoy se respira. Aparece el libro ilustrado por Luis Seoane, director artístico de la nueva editorial, con esa gracia, esa finura de intuición y maestría por todos reconocidas en él.

18 Sobre las relaciones entre las dos colecciones, véase el trabajo de Fernando Larraz 2009, quien dedica un pasaje de su texto a la presencia de Antonio Machado.

19 En relación con esta operación, cabe también recordar la nota publicada por Lorenzo Varela en la sección "Mirador" del $n^{\circ} 4$, titulado "Sociedad anónima de irresponsabilidad ilimitada", en el que expresa su indignación ante la reedición por Espasa-Calpe de España, de la Antología de la poesía romántica española, de Manuel Altolaguirre, en que se suprime el nombre del antólogo, lo que Varela identifica como el "método falangista de matar el nombre cuando el hombre no está a mano" (nº 4, p. 37).

20 Con respecto a la causa probable de la salida de Cuadrado y Seoane de Emecé, tres son las versiones que circulan: que se negaron a editar un libro del entonces embajador de la España franquista en la Argentina, que hicieron lo propio con una novela de Camilo José Cela, y que se solidarizaron con Lorenzo Varela ante los ataques recibidos por su militancia comunista. Una cuarta sería la escasa rentabilidad de los libros de temas y autores gallegos (De Diego 2006: 99, Pérez Rodríguez 2009: 112). El carácter conflictivo de la salida de Seoane y Cuadrado de Emecé, en cualquiera de las tres hipótesis, podría explicar el hecho de que, al reseñar el libro ¡Eh, los toros! para el primer número de De Mar a Mar, Lorenzo Varela omita, tanto en el encabezado como en el texto mismo de la reseña, el nombre del sello que lo editó, es decir, Emecé. Lo mismo cabría conjeturar con respecto a la ausencia de publicidad de dicha editorial en las páginas de la revista. 
Formato, composición tipográfica, ilustraciones y contenido constituyen un acabado ejemplo que no dejará de influir en el auge que el libro argentino está cobrando de día en día en los mercados en lengua española. $\left(\mathrm{n}^{\mathrm{o}} 2, \mathrm{p} .52\right)$

Si en este pasaje el posicionamiento político del autor, coincidente con el del editor, y el incidente que involucra a ambos, es un factor que acrecienta el interés del libro reseñado, en otras ocasiones uno y otro aspecto se mantienen discriminados. Tal es el caso de la reseña, escrita por Lorenzo Varela e incluida en el número inaugural de la revista, que da cuenta de la publicación de la biografía de Goya escrita por Ramón Gómez de la Serna, editada por Poseidón, y publicitada en el mismo $\mathrm{n}^{\mathrm{o}} 1 \mathrm{y}$ también en el $n^{\circ} 2$ :

Pero ha desaparecido el Palacete de la Moncloa al que "ha destruido la revolución última", como consigna Gómez de la Serna en este Goya que escribió para la Editorial Poseidón. (...) Ni una palabra sobre la artillería franquista y la aviación alemana que derribaron el Palacete, nada sobre los hombres de la República que salvaron el Museo del Prado, y el particular del de Alba, entre otras cosas. Pero en un libro sobre Goya, en el que se hace esta alusión oficial a la destrucción del Palacete por "la revolución", no era posible decir nada de esto. Aparte de la turbiedad moral, de la manquedad humana de que siempre ha padecido Gómez de la Serna, en este Goya, como en toda su obra, se impone como uno de nuestros más grandes escritores. $\left(\mathrm{n}^{\mathrm{o}} 1\right.$, pp. 47-48)

La lectura de Lorenzo Varela, quien comparte lugar en el catálogo de Poseidón con Gómez de la Serna ${ }^{21}$, destaca las virtudes del texto y, sobre todo, de su edición con "las 68 impecables reproducciones que nos brinda", pero, al mismo tiempo y sin que esto afecte lo anterior, hace foco en la alusión a la destrucción del Palacete de la Moncloa durante la Guerra Civil española, lo que da pie a la crítica respecto del posicionamiento político del autor en relación con la dictadura instaurada tras el conflicto bélico. La citada reseña constituye un ejemplo relevante del modo en que conviven, dentro de la consideración de un mismo objeto -el Goya de Gómez de la Serna, editado por Poseidón- y determinando en este caso valoraciones opuestas entre sí, dos factores vinculados a los rasgos programáticos de la revista: por un lado, las relaciones de directivos y colaboradores con la actividad editorial y, por el otro, el posicionamiento político de los mismos integrantes del grupo interno.

\section{A modo de cierre: la continuidad de un proyecto y de sus relaciones editoriales}

Al comienzo, el presente artículo hacía referencia a la continuidad de De Mar a Mar en otra publicación periódica, Correo Literario, fundada y llevada adelante por un grupo de intelectuales y artistas exiliados bajo la figura de sus tres directores gallegos: Luís Seoane, Lorenzo Varela y Arturo Cuadrado. Aunque no se reduce a ella sino que también atañe a los dos lineamientos programáticos antes puntualizados -militancia antifascista y voluntad de integración con el campo cultural local-, la presencia de directivos y colaboradores comunes con De Mar a Mar determina la persistencia de sus conexiones editoriales en la nueva revista, particularmente atenta al desarrollo del mercado del libro en la Argentina y en Latinoamérica durante toda su andadura. En este sentido, podría afirmarse que Correo Literario se constituye sobre la base de una red de relaciones editoriales que se pueden advertir en su predecesora, lo que explica la presencia destacada, en las páginas del periódico quincenal, de las editoriales Nova, Poseidón, Losada, El Ateneo, Sudamericana y la Imprenta López ${ }^{22}$. El seguimiento de un último ejemplo acierta a ilustrar esta continuidad de las redes editoriales del exilio gallego en Buenos Aires, entre De Mar a Mar y Correo Literario.

Una de las dos colaboraciones originales incluidas en el número 1 de De Mar a Mar es

21 Véase supra la n. 9. Ramón Gómez de la Serna era por entonces uno de los autores predilectos de la editorial de Joan Merli, en la que también vieron títulos como Ismos, John Ruskin y Velázquez, sólo por mencionar los incluidos en la publicidad editorial de De Mar a Mar $\left(\mathrm{n}^{\mathrm{os}} 3,4,5\right.$ y 6). Sobre la relación entre el escritor y su editor en Buenos Aires, véase el trabajo de Pura Fernández 2011 en torno a su epistolario.

22 Un abordaje de las relaciones entre Correo Literario y el mercado editorial de la época, apoyado en el análisis de sus textos críticos y sus avisos publicitarios, puede encontrarse en Gerhardt 2016. 
el texto titulado "De cómo vino al mundo Félix Muriel", presentado como avance de una novela titulada Tratados y confidencias de Félix Muriel, de Rafael Dieste (n ${ }^{\circ}$ 1, pp. 2631). Finalmente, el libro se publicará en 1943 con el título de Historias e invenciones de Félix Muriel -aunque el capítulo anticipado no formará parte de esta primera edición-, y verá la luz dentro de la citada colección Camino de Santiago de la Editorial Nova, dirigida por Luis Seoane. La publicidad editorial del $\mathrm{n}^{\circ} 4$, de marzo de 1943 lo incluye, junto con una breve descripción del libro -"narraciones y cuentos de este gran escritor en donde revela la fuerza y frescura de su inconfundible estilo entre los mejores escritores contemporáneos", y el detalle de las diferentes características de los ejemplares numerados que componen la edición, "ilustrada valiosamente por Luís Seoane", desde aquéllos acompañados por dibujos originales o coloreados por el artista hasta los de edición corriente y los fuera de comercio. Finalmente, la obra será objeto de una elogiosa reseña escrita por Arturo SerranoPlaja e incluida en el séptimo y último número de De Mar a Mar, fechado en junio de 1943 al igual que la impresión del libro ( $\mathrm{n}^{\mathrm{0}} 7, \mathrm{pp}$. 38-40).

En noviembre de ese mismo año, 1943, otra reseña más extensa pero igualmente elogiosa del libro de Rafael Dieste, firmada por Lorenzo Varela, abre la sección "Libros y autores" del primer número de Correo Literario, y se cierra ponderando, precisamente, el arte de tapa e interior: "Dibujos de Luís Seoane -dueño de sus recursos, decidido- ilustran con fidelidad el libro, y en ellos encuentran estas Historias e Invenciones esa playa propicia, natural y fantástica, en que mirarse y reconocerse" $\left(\mathrm{n}^{\mathrm{o}} 1, \mathrm{p}\right.$. 6). De este modo, el itinerario trazado por este libro, título emblemático de la literatura gallega nacida en las playas del exilio, a través de las páginas de De Mar a Mar y desde ellas al nacimiento de Correo Literario, da resumida cuenta de la extensión de las redes editoriales tendidas por el exilio gallego en la Argentina.

\section{Referencias bibliográficas}

Caudet, Francisco (2004): El exilio republicano. Las revistas literarias (1939-1971). Alicante: Universidad de Alicante.

De Diego, José Luis (2006): “1938-1955. La “época de oro’ de la industria editorial”, en J. L. de Diego (dir.), Editores y políticas editoriales en Argentina (1880-2000). Buenos Aires: Fondo de Cultura Económica, pp. 91-123.

Dieste, Rafael (1995): Obras completas. Tomo V. Epistolario. Sada: Ediciós do Castro.

Dolinko, Silvia (2010): "Guerra, exilio e imágenes transatlánticas. Un análisis de la revista De mar a mar", Ciberletras-Revista de crítica literaria y de cultura - Journal of literary criticism and culture 23 (http:// www.lehman.cuny,edu/ciberletras/v23/dolinko.html).

Fernández, Pura (2011): “El epistolario de Ramón Gómez de la Serna a Joan Merli (1942-1950): hacia los libros creadores", Bulletin of Spanish Studies LXXXVIII/7-8, pp. 287-298.

Gerhardt, Federico (2015a): "Asociacionismo gallego y mercado del libro en la Buenos Aires del medio siglo: dos proyectos editoriales de Luis Seoane”, Madrygal. Revista de Estudios Gallegos 18, pp. 457467 (https://revistas.ucm.es/index.php/MADR/article/view/48569/45373).

(2015b): "Exiliados en la 'edad de oro'. Redes políticas y culturales del exilio gallego en el campo editorial argentino de la década del cuarenta: publicaciones periódicas, colecciones y editoriales", Revista Eletrônica da ANPHLAC 19, pp. 72-103 (http://revistas.fflch.usp.br/anphlac/article/view/2360/2195).

(2016): "Independencia crítica y compromiso de empresa: Correo Literario (1943-1945) y el mercado editorial", en V. Delgado y G. Rogers (coords.), Tiempos de papel. Publicaciones periódicas argentinas. La Plata: Universidad Nacional de La Plata, pp. 263-284.

González Ledo, José (2008): La peña gallega del Tortoni. Buenos Aires: Alborada.

Larraz, Fernando (2009): "Política y cultura. Biblioteca Contemporánea y Colección Austral, dos modelos de difusión cultural", Orbis Tertius. Revista de Teoría y Crítica Literaria 15 (http://www.orbistertius. unlp.edu.ar/article/view/OTv14n15d01/5007).

Osuna, Rafael (2004): Las revistas literarias. Cádiz: Universidad de Cádiz.

Pérez Rodríguez, María Antonia (2004): “Luis Seoane e o 'Grupo Tortoni’ dentro do exilio galego en Bos Aires: 1937-1953”, en VV.AA., Xornadas sobre Luis Seoane. A Coruña: Xunta de Galicia, pp. 125-140. (2005): "Estudo introdutorio", en X. López García y R. Aneiros Díaz (coords.), Lorenzo Varela en revistas culturais de México e Bos Aires. Santiago de Compostela: Consello da Cultura Galega, pp. 13-133. 
(2009): "As editoriais no exilio arxentino/Las editoriales en el exilio argentino", Galegos=Gallegos 7, pp. 110-118.

(2013): "Análise da correspondencia entre Maruja Mallo e Alfonso Reyes (1938-1945)", Madrygal. Revista de Estudios Gallegos 16, pp. $73-86$ (https://revistas.ucm.es/index.php/MADR/article/ view/42990/40795).

(2014): "Correspondencia Maruja Mallo-Alfonso Reyes (1938-1945). Edición anotada", Madrygal. Revista de Estudios Gallegos 17, pp. $81-98$ (https://revistas.ucm.es/index.php/MADR/article/ view/45740/42986).

Pochat, María Teresa (1991): "Editores y editoriales", en N. Sánchez-Albornoz (comp.), El destierro español en América. Un trasvase cultural. Madrid: Siruela / Sociedad Estatal Quinto Centenario, Instituto de Cooperación Iberoamericano, pp. 163-176.

Rivera, Jorge B. (1998): El escritor y la industria cultural. Buenos Aires: Atuel.

Sánchez Vigil, Juan Miguel y María Olivera Zaldua, (2012): "La Colección Austral: 75 años de cultura en el bolsillo (1937-2012)", Palabra Clave 1/2, pp. 29-47.

Varela, Lorenzo (2001): "De Mar a Mar", en L. Varela, Ensayos, conferencias y otros escritos. II. Sada: Ediciós do Castro (Col. Biblioteca del Exilio), pp. 165-169 (http://www.palabraclave.fahce.unlp.edu.ar/ article/view/PCv1n2a03/1980).

Zuleta, Emilia de (1999): Españoles en la Argentina. El exilio literario de 1936. Buenos Aires: Atril. 